\title{
A novel flame retardant material for fabricated cotton and its mixture with polyester $(50 / 50)$
}

alaa abdelmoaty ( $\sim$ 3laasalah.86@gmail.com )

National Research Centre

Adly Abdalla Hanna

National Research Centre

Ahmed Amr

National Research Centre

Ashraf Abou-Okeil

National Research Centre

\section{Research Article}

Keywords: Ammonium polyphosphate, Montmorillonite, Melamine, Cotton fabric, Limiting oxygen index (LOI) and Flame retardant

Posted Date: February 2nd, 2022

DOI: https://doi.org/10.21203/rs.3.rs-1311636/v1

License: (c) (1) This work is licensed under a Creative Commons Attribution 4.0 International License. Read Full License 


\section{Abstract}

Cotton fibers found large applications especially in the woven and non-woven industrials. The cotton fibers exhibit good properties but it have main drawback because it is easy and rapid flammable. To overcome on this drawback, several works were done. These works focused on the properties of fibers or treated with flame retardant materials. The present work aimed to study the flammability of fibers in presence of flame retardant materials. A novel flame retardant material was prepared by using simple method. The produced sample contains the Ammonium poly phosphate (APP), montmorillonite (Mt) and Melamine (M). The prepared samples were characterized by using Fourier transforms infrared (FTIR) spectroscopy, Scanning electron microscope (SEM), X-ray diffraction (XRD) and Thermal gravimetric analysis (TGA). Also, the flammability of the treated samples was done by using the limiting oxygen index (LOI). The results of characterization indicated that the flame retardant formula was incorporated into the fibers as shown SEM. The mechanism of the incorporation was discussed, the flammability results show that the values for LOI increases from 19.2 for $100 \%$ cotton to 26.2 for treated samples.

\section{Introduction}

In spite of huge amounts of cotton fibers were used in different industries such as garments, decorations, towels, decoration and other industries still now the spinning and the waving in the main demand of cotton fibers (1). The cotton fibers have several advantages such as eco-friendly, biodegradability, softness, breathability, non-toxicity, low density and low costs (2). Moreover it is not expensive when fabricated. On other hand, cotton fibers exhibit some disadvantages properties such as it easy and high flammable, when the fire starts, it spread easy through the fibers besides evolving a dense smoke which may great environmental pollution and great damage for the human. Owing to this property, several works were done to improve the properties of cotton fibers before or during the fabrication. These modifications go in two ways. The first one is improvements the fibers by physical or chemical treatments. It is found that grafting cotton fibers with less flammable polymer or some inorganic oxides such as $\mathrm{ZnO}, \mathrm{TiO}_{2}, \mathrm{Al}_{2} \mathrm{O}_{3}$ and $\mathrm{Fe}_{2} \mathrm{O}_{3}$ are more acceptable route because it may improve the mechanical properties and increase the action towards the dyes. The second route goes to use flame retardant materials to reduce the spread of the flame through the fibers. Several works were done to form formulates flame retardant for cotton fibers (3-9). Some of these formulate containing organic, inorganic materials and ores (10-16). In general choose of the flame retardants formulate is very difficult for the environmental pollution, costs and the evolved and the residual flame burning. Some of the flame retardant formulates have advantages and other exhibits disadvantages. In this field the containing nitrogen compounds such as melamine phosphate (MP) is a typical halogen free as flame retardant for cotton fibers because the evolving of nitrogen and phosphoric acid resulting a synergetic effect (17). The main works in this target is how the flame retardant attached or incorporated through the cotton fibers, this process may carry before using the fibers. In previous work, Hanna et al carried several works to formulate flame retardant materials (18-24). They prepared nano-particles of ammonium polyphosphate and used successfully as flame retardants for polypropylene. They found that the nano-particles increase 
the flame retardancy of ammonium polyphosphate (APP) but they found that the main drawback of APP is its water solubility. To overcome on this solubility, they formed a formula of APP and montmorillonite (Mt), which is reach with $\mathrm{SiO}_{2}$ and $\mathrm{Al}_{2} \mathrm{O}_{3}$. The study shows that the addition of Mt increases the efficiency of APP as flame retardant (25). The authors suggested a different formula and applied to the cotton fibers. As continuations of this policy, in this work, a new formula containing APP, Mt and Melamine (M) was prepared and chemically treated to attach the cotton fibers. The work devoted to study the action of this formula on the flammability of the cotton fibers.

\section{Experimental \\ 2.1. Materials}

Ammonium polyphosphate (APP) was prepared previously (18), Melamine with purity $99 \%$ and Egyptian montmorillonite k10 [Mt] were purchased from Alfa Aesar Company (18), Germany. Phosphoric acid and methanol, (HPLC) were obtained from Sigma-Aldrich Company, Germany. Plain weaves of 50/50\% cotton/polyester (PET) $160 \mathrm{~g} / \mathrm{cm}^{2}$ and $100 \%$ cotton $120 \mathrm{~g} / \mathrm{cm}^{2}$ fabrics were supplied by Misr Spinning and Weaving Co., Mehalla El Kobra, Egypt. 3-glycidyl-oxy-propyl trimethoxysilane (GPTMS, 99\%) and 2propanol (99\%) were provided from Aldrich and 1-Methlylimidazole was supplied from BASF, hydrochloric acid $(\mathrm{HCl})$ grade in lab.

\subsection{Methods}

\subsubsection{Synthesis of MtAPPM}

MtAPPM was synthesized by adding $150 \mathrm{ml}$ of distilled water and $40 \mathrm{~g}$ of APP in a 400-ml beaker fitted by stirrer. The mixture was stirred for $30 \mathrm{~min}$ at room temperature and heated to $100 \circ \mathrm{C}$ for $2 \mathrm{~h}$ to form solution of APP. Then, $12 \mathrm{~g}$ of Mt was added and the mixture was stirred for $18 \mathrm{~h}$ at room temperature and then heated to $100^{\circ} \mathrm{C}$ for $1 \mathrm{~h}$. Montmorillonite Ammonium polyphosphate (MtAPPM) was obtained as intermediate. In three-necked flask, $42 \mathrm{~g}$ of melamine was dispersed into $500 \mathrm{ml}$ methanol. The synthesized (MtAPPM) was added into the flask slowly at $100-110{ }^{\circ} \mathrm{C}$ and the reaction continued for $8 \mathrm{~h}$. The solution was filtered, washed three times with methanol, and dried at room temperature as shown in Fig. 1. The final product (MtAPPM) was $200 \mathrm{~g}$ in pale white color and was grinded to be fine powder (17).

\subsubsection{Hydrolysis of GPTMS (26).}

Hydrochloric acid $(1.22 \mathrm{~mL}, 0.01 \mathrm{M})$ was added to a solution of 3-glycidyloxypropyltrimethoxysilane (GPTMS, $10 \mathrm{ml})$ in 2-propanol $(100 \mathrm{ml})$ and the resulting mixture stirred at room temperature for $2 \mathrm{~h}$. The resulting bath containing hydrolyzed GPTMS was used in the second step as shown in Figure 2.

\subsubsection{Fabric treatment}

Samples of fabric $(20 \mathrm{~cm} \times 20 \mathrm{~cm})$ Cotton/PET and 100\% Cotton were immersed in the finishing bath containing $50 \mathrm{ml}$ hydrolyzed GPTMS and different concentration between $(0.05,0.1,0.15 \mathrm{gm})$ of modified 
Melamine ammonium polyphosphate (MtAPPM) suspended in $50 \mathrm{ml}$ distilled water with magnetic stirring for $30 \mathrm{~min}$. then we using sonication to give good suspension, 1-Methylimidazole (few drops).

The fabric samples were squeezed to $80 \%$ wet pick-up, followed by drying at $100^{\square} \mathrm{C}$ for 3 min. then cured at different temperatures $\left(120,140,160^{\square} \mathrm{C}\right)$ for 3 min. All samples were washed thoroughly with tap water to get rid of the unreacted materials then dried at room temperature overnight as shown in Fig. 2.

\subsection{Characterization Techniques}

The dried samples were exposed to different techniques as follows.

\subsubsection{Fourier transforms infrared (FTIR) spectroscopy}

Fourier transforms infrared (FTIR) spectroscopy to give the main functional groups on the obtained samples was done using a $\mathrm{KBr}$ disk technique and FTIR 6500 spectrometer (JASCO, Japan) in the range of $400-4000 \mathrm{~cm}^{-1}$.

\subsubsection{X-ray diffraction (XRD) analysis}

X-ray diffraction (XRD) analysis to determine the main crystalline was performed with power D8 ADVANCE diffractometer (Germany) using CuKa radiation $\left(1.542^{\circ} \mathrm{A}, 40 \mathrm{KV}, 40 \mathrm{~mA}\right)$ in the $2 \theta$ range of 480. The acquisition parameters were as: a step size of 0.02 and a step time of $0.4 \mathrm{~s}$.

\subsubsection{Scanning electron microscope}

The surface morphologies of the samples were carried out using a Quanta 200 FEG scanning electron microscope (SEM) (Quanta) at an accelerating voltage of $30 \mathrm{kV}$.

\subsubsection{Thermal analysis (TGA)}

Thermal analysis (TGA) was performed by USA Berkin - Elmer thermo-gravimeter. Samples of approximately $10 \mathrm{mg}$ were heated from $50^{\circ} \mathrm{C}$ to $800^{\circ} \mathrm{C}$ with heating rate $10 / \mathrm{m}$ under a nitrogen atmosphere, and the flow of nitrogen was $50 \mathrm{~mL} / \mathrm{min}$.

\subsubsection{Flame retarding test.}

The flame retardant properties of the cotton fabrics were tested using limited oxygen index LOI apparatus 4589-2 ASTM D 2863, Elevated- Temperature Oxygen Index ISO 4589-3, UKNaval Engineering standard NES 714 which measure the percentage of oxygen that has to be present the supported burning of the samples.

\section{Results And Discussion}

\subsection{Fourier transforms infrared (FTIR) spectroscopy}


Figure 3. represents the IR absorption of the dry sample (MtAPPM) and that attached with fabricated cotton and cotton/PET (50/50) samples. It is observed that several bands derived from the prepared samples and that treated with the cotton-polymer bands. At first, there are four IR shoulders 3469, 3419, 3329 and $3128 \mathrm{Cm}^{-1}(28)$. The appearance of their shoulders attributed to the primary amines of the functional groups of melamine. Three absorption deep peaks were shown on the IR chart at 1650, 1551 and $813 \mathrm{Cm}^{-1}$ which specified the triazine ring of the melamine compounds. Furthermore a groups of peaks returned to the Mt were observed at 362,1085 and $786 \mathrm{Cm}^{-1}$ due to the $\mathrm{OH}$ and Si-O stretching vibration (27). Also, two sharp peaks at 1117 and $1081 \mathrm{Cm}^{-1}$ indicate to the attachment of the APP (17). Moreover, two new peaks were appeared. These two bands may indicate to the formation of MtAPPM prepared compounds. From the analysis of their data, it may conclude that there is a chemical reaction between the precursor materials, melamine, Mt and APP resulting a new compound MtAPPM.

\subsection{X-ray diffraction (XRD) analysis.}

To study the crystallinity of the produced samples, the XRD was performed. Fig. 4. represents the X-ray diffraction of prepared samples (MtAPPM). On the x-ray chart many sharp diffraction peaks were observed on the value of 2-theta ranges from 2.5-30 (27). By comparison between the obtained Fig. 4 and that carried previously for APP and Melamine, it may conclude that there is a chemical reaction between the precursor materials.

\subsection{Scanning electron microscope}

Figure 5. represents the imagines of the produced samples. The photo shows that the material MtAPPM is homogeneous granules with agumulations. After treating the cotton and cotton/PET with MtAPPM, the photos indicates that both the fibers like strings before treating, while after attaching by MtAPPM a circular grown, distributed randomly and partially coating the fibers.

\subsection{Thermal gravimetric analysis (TGA)}

The thermal stability of the cotton fibers, the cotton/PET (50/50), the prepared dry sample (MtAPPM) and both of the cotton and the mixture treated with the prepared samples as flame retardant materials were performed and recorded in Fig. 6 . The TG profiles of the five samples show that the thermal degradation of the pure cotton and cotton/PET samples behaves three steps of degradation. The first step starts at room temperature and ending at 300 and $320^{\circ} \mathrm{C}$, for cotton and cotton/PET fibers respectively. This step may due to the volatilization of moisture and the volatile materials. The second step represents the main degradation of fibers to the parent gases such as $\mathrm{CO}, \mathrm{CO}_{2}$ and $\mathrm{H}_{2} \mathrm{O}$ vapors. The third step represents the char formation which is remaining stables till $450^{\circ} \mathrm{C}$ and $440{ }^{\circ} \mathrm{C}$ respectively. It is observed that all TG curves are nearly similar with slight difference in $\mathrm{T}_{\text {Onset }}$ and $\mathrm{T}$ outset due to structure the fiber such as the crystallinity and the degree of polymerization.

The TG curve of the MtAPPM behaves different character than that of the fibers, where it starts to degrade gradually till $420^{\circ} \mathrm{C}$. This character may due to the organic fragments of the organic-inorganic frame. For the cotton and cotton/PET treated with MtAPPM, the mixed samples start to degredate at 
lower than the pure fibers as show from the $T_{\text {Onset, }}$ Table 1. It is noted that the treated samples degredate gradually and wide range of temperature than that untreated samples. These findings indicate that it is less flammable than untreated samples.

\subsection{Flame retardant test}

The testing of use MtAPPM material as flame retardant for cotton fiber and cotton/PET (50/50) were carried out by using LOI. The LOI is simple method and inexpensive. It definite as the minimum of oxygen in an oxygen/nitrogen ratio, it is value express on the ability of materials to burn. It is well known that the normal air contains $20 \%$ oxygen, owing to this fact the higher LOI value indicates that the materials are un flammable while the lower LOI value than $20 \%$ indicates that the materials are higher flammable. The materials exhibits LOI from 24 to 27 are difficult to flammable, while the LOI value higher than 27 are inflammable materials.

Table 1. represents the values of LOI of cotton fibers, cotton/PET (50/50), before treatments and their values after treatment with different amount of MtAPPM. The values of LOI for the cotton fibers equal to 19.2 , this means that it is flammable materials. As $0.05 \mathrm{gm}$ of MtAPPM added to $100 \mathrm{gm}$ cotton fibers, the value of LOI increases to become 21.6 and it increases to 26.4 when $0.15 \mathrm{gm}$ of MtAPPM added. This finding indicates that the cotton fibers converted from flammable substance to nearly the inflammable materials. In the case of cotton/PET fibers under the same conditions, the LOI equals to 28.1. This means that the action of MtAPPM is more effective as flame retardant material for the mixture (cotton/PET) than pure cotton fibers but in all cases it is effective additives.

Moreover, the LOI were evaluated at three different cure temperatures at 120, 140 and $160 \mathrm{OC}$, for the treated and untreated fibers. The results show that the values of LOI increase with increasing the curing temperatures. The higher value was obtained at curing temperature at $160^{\circ} \mathrm{C}$.

The residual ash of native cotton and its mixture with PET (50/50) and after treatment with the prepared MtAPPM material are shown at Figure 7. This photo indicates that the cotton fiber burned completely without any residual of the ash while for the mixture shows a slight residual, this may due to the polyester content (29). For the two fiber samples, the effects of the flame retardant on the flammability are clear, while the residual ash is greater. From this result, it may decide that the flammability of fibers before and after treatment became following sequences:

Cotton greater than Cotton/PET (50/50) greater than cotton/MtAPPM greater than Cotton/PET (50/50)/MtAPPM. This arrangement is agreement with the results of the thermal analysis. 
Table 1

Effect of concentration of (MtAPPM) on the limiting oxygen index ( $\mathrm{LOI}$ )

\begin{tabular}{|lll|}
\hline Type of fabrics & Conc. Of MtAPPM g/100 $\mathbf{~ m l}$ & Limiting Oxygen Index (LOI) \\
\hline Control & 0 & 19.2 \\
$100 \%$ cotton fabric & 0.05 & 21.6 \\
& 0.1 & 22.2 \\
& 0.15 & 26.4 \\
\hline Control & 0 & 21.2 \\
$50 / 50 \%$ cotton/PET & 0.05 & 22.2 \\
& 0.10 & 26.2 \\
& 0.15 & 28.1 \\
\hline
\end{tabular}

Table 2

Effect of curing temperature on the limiting oxygen index (LOI)

\begin{tabular}{|lll|}
\hline Type of fabrics & Curing temperature ${ }^{\square} \mathbf{C}$ & Limiting Oxygen Index (LOI) \\
\hline Control & 0 & 19.2 \\
100\% cotton fabric & 120 & 22.3 \\
& 140 & 26.6 \\
& 160 & 26.2 \\
\hline Control & 0 & 21.2 \\
$50 / 50 \%$ cotton/PET & 120 & 22.8 \\
& 140 & 28.0 \\
& 160 & 28.2 \\
\hline
\end{tabular}

\section{Conclusion}

From the analysis of the obtained data from the characterization of the prepared sample, it may conclude that the prepared flame retardant material containing ammonium poly phosphate, montmorillonite and melamine are incorporated through the cotton fibers. From the thermo- gravimetric analysis and limiting oxygen index, it may clear that the prepared material could be used as flame retardant for fiber, where the LOI increases from 19.2 to 26.2 for $100 \%$ cotton and for the Cotton/PET from 21.2 to 28.2 .

\section{Declarations}

\section{Acknowledgement}


The authors submit their acknowledgment to their institute (National Research Centre, Cairo, Egypt) for encouragement the team work to do this work.

\section{References}

1. G. Laufer, F. Carosio, R. Martinez, G. Camino, J.C. Grunlan, Growth and fire resistance of colloidal silica-polyelectrolyte thin film assemblies. J. Colloid Interface Sci. 356, 69-77 (2011). https://doi.org/10.1016/j.jcis.2010.12.072

2. C. Dong, Z. Lu, P. Wang, P. Zhu, X. Li, S. Sui, L. Zhang, J. Liu, Flammability and thermal properties of cotton fabrics modified with a novel flame retardant containing triazine and phosphorus components. Text. Res. J. 87, 1367-1376 (2017). https://doi.org/10.1177/0040517516652349

3. A.R. Horrocks, Flame retardant challenges for textiles and fibres: new chemistry versus innovatory solutions. Polym. Degrad. Stab. 96, 377-392 (2011). https://doi.org/10.1016/j.polymdegradstab.2010.03.036

4. F. Bosco, R.A. Carletto, J. Alongi, L. Marmo, A. Di Blasio, G. Malucelli(2013). Thermal stability and flame resistance of cotton fabrics treated with whey proteins, Carbohydrate polymers, 94: 372-377, https://doi.org/10.1016/j.carbpol.2012.12.075,https://doi.org/10.1016/j.carbpol.2012.12.075

5. A. Abou-Okeil, A. El-Shafie, A. Hebeish, Chitosan phosphate induced better thermal characteristics to cotton fabric. J. Appl. Polym. Sci. 103, 2021-2026 (2007). https://doi.org/10.1002/app.25322

6. A. Hebeish, A. Waly, A. Abou-Okeil (1999). Flame retardant cotton, Fire and materials, 23: 117-123, https://doi.org/10.1002/(SICI)1099-1018(199905/06)23:3\%3C117::AID-FAM675\%3E3.0.CO;2-Y

7. A. Abou-Okeil, S. El-Sawy, F. Abdel-Mohdy, Flame retardant cotton fabrics treated with organophosphorus polymer. Carbohydrate polymers 92, 2293-2298 (2013). https://doi.org/10.1016/j.carbpol.2012.12.008

8. A. Abou-Okeil, A. El-Shafie (2011). Urea phosphate/ $\beta$-cyclodextrin inclusion complex to enhance thermal behavior of cotton fabric, Carbohydrate polymers, 84: 593-598, https://doi.org/10.1016/j.carbpol.2010.12.035

9. E. Weil, S. Levchik, Flame retardants in commercial use or development for textiles. J. Fire Sci. 26, 243-281 (2008). https://doi.org/10.1177/0734904108089485

10. Z. Wu, H. Wang, X. Tian, X. Ding, M. Xue, H. Zhou, K. Zheng, Mechanical and flame-retardant properties of styrene-ethylene- butylene-styrene/carbon nanotube composites containing bisphenol A bis(diphenyl phosphate). Composites Science and Technology 82, 8 (2013). http://dx.doi.org/10.1016/j.compscitech.2013.04.003

11. G. Huang, S. Wang, Song, p., Wu, C. Chen, S. X. Wang, Combination effect of carbon nano-tubes with graphene on intumescent flame retardant polypropylene nano-composites Part A (Applied Science, 2014) 0 and Manufacturing, 59: 18, https://doi.org/10.1016/j.compositesa.2013.12.010

12. A. Horrocks, Flame retardant challenges for textiles and fibres: New chemistry versus innovatory solutions. Polym. Degrad. Stab. 96, 377 (2011). 
http://dx.doi.org/10.1016/j.polymdegradstab.2010.03.036. 0

13. A. Horrocks (2013). Textile flammability research since 1980 Personal challenges and partial solutions, Polymer Degradation and Stability, 98: 2813, http://dx.doi.org/10.1016/j.polymdegradstab.2013.10.004

14. G. Beyer, Short communication: Carbon nano-tubes as flame retardants for polymers. Fire Mater. 26, 291 (2002). https://doi.org/10.1002/fam.805. 0

15. Q. Kong, R. Lv, S. Zhang (2008). Flame retardant and the degradation mechanism of high impact polystyrene/Fe-montmorillonite nano-composites, Journal of Polymer Research, 15: 453, https://doi.org/s10965-008-9191-5

16. M. Costache, D. Wang, Heidecker, M. E. Manias, C. Wilkie (2006). The thermal degradation of poly(methyl methacrylate) nanocomposites with montmorillonite, layered double hydroxides and carbon nano-tubes., Polymers for Advanced Technologies, 17: 272, https://doi.org/10.1002/pat.697

17. G. Makhlouf, M. Hassan, M. Nour, Y. Abdelmonem, A. Abdelkhalik (2017). A Novel Intumescent Flame Retardant: Synthesis and Its Application for Linear Low-Density Polyethylene, Arabian Journal of Science and Engineering, 42:4339-4349, https://doi.org/ 10.1007/s13369-017-2443-0

18. M. Sherief, A. Hanna, A.S. Abdelmoaty, Synthesis and characterization of nano-sized ammonium polyphosphate. Canadian Journal of Applied Sciences 3, 39-49 (2014). http://www.icdtdi.ca

19. M. Sherief, A. Hanna, A. Abdelhakim, A.S. Abdelmoaty, The flammability of polypropylene nano-sized ammonium polyphosphate system. Canadian Journal of Applied Sciences 3, 94-99 (2014). http://www.icdtdi.ca

20. M. Sherief, A. Hanna, A.S. Abdelmoaty, Studies on the effect of diatomite on the flammability of ammoniumpolyphosphate /polypropylene. International Journal of ChemTech Research 9, 822-830 (2016). https://www.researchgate.net/publication/304953515

21. A. Hanna, E. Souaya, A.S. Sherief., Abdelmoaty, Studies on The Effects of Kaolin and Modified Kaolin on the Flammability of APP/PP System. Egypt. J. Chem. 60, 205-219 (2017). https://doi.org/10.21608/ejchem.2017.593.1005

22. A. Hanna, M. Nour, M. Elsherief, E. Souaya, A.S. Abdelmoaty, Fire Performance of PolyPropylene Treated with Ammonium Polyphosphate and Kaolin. Egypt. J. Chem. 60, 937-944 (2017). https://doi.org/10.21608/EJCHEM.2017.1509.1110

23. A. Hanna, A.S. Abdelmoaty, M. Sherief (2019). Synthesis, Characterization, and Thermal Behavior of Nano-particles of $\mathrm{Mg}(\mathrm{OH})_{2}$ to Be Used as Flame Retardants, Journal of Chemistry, 2019: 1-6, https://doi.org/10.1155/2019/1805280

24. M. Marzouk., A. Hanna, A.S. Abdelmoaty, A. Abou-Okeil, A. Ahmed, Preparation and characterization of flame retardant cotton fabrics. Biointerface Journal in applied Chemistry 10, 5296-5300 (2020). https://doi.org/10.33263/BRIAC102.296300

25. A. Hanna, M. Nour, E. Souaya, M. Sherief, A.S. Abdelmoaty(2018). Studies on the flammability of polypropylene/ammonium polyphosphate and montmorillonite by using the cone calorimeter test , 0 . Chemistry, 16: 108-115, https://doi.org/10.1515/chem-2018-0013 
26. A. El-Sayed, A. Amr, M. Omnia, M. Kamel, M. Manal, M. El-Saidi, M. Ahmed, E. Abdelhamid (2020). Eco-friendly fabric modification based on AgNPs@Moringa for mosquito repellent applications., Cellulose, 27:8429-8442., https://doi.org/10.1007/s10570-020-03355-8

27. M. Hassan, M. Nour, Y. Abdelmonem, M. Makhlouf, A. Abdelkhalik(20160. Synergistic effect of chitosan-based flame retardant andmodified clay on the flammability properties of LLDPE, Polymer Degradation and Stability, 133: 8-15, https://doi.org/10.1016/j.polymdegradstab.2016.07.011

28. S. Adikary, D. Wanasinghe (2015). Characterization of locally available montmorillonite clay using FTIR technique, In: Proceedings of 8th International Research Conference, KDU, pp. 163-169

29. T. Kashiwagi, F. Du, J. Douglas, I. Winey, R. Harris, J. Shields, Nano-particle networks reduce the flammability of polymer nano-composites. Nat. Mater. 4, 928, (2005). https://doi.org/10.1038/nmat1502.

\section{Figures}

Ammonium polyphosphate<smiles>CC(CP(=O)(O)O)(OP(=O)(O[Na])C(C)(C)OP(=O)(O)O)P(=O)(O)O</smiles>

(I)- APP

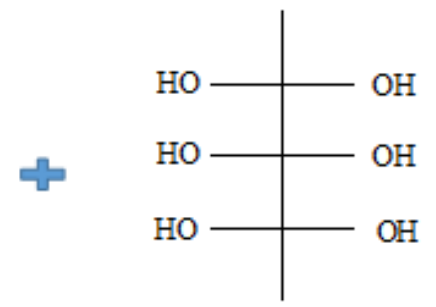

$\mathrm{Mt}$<smiles>O=P(O)(O)[Os]</smiles><smiles>CP1(=O)OCP(=O)(O)O1</smiles><smiles>CC1(O)OP(C)(=O)P1(=O)O</smiles><smiles>CC(C)(O)C(O)(O)C(C)(O)O</smiles>

1- Stir for $18 \mathrm{~h}$ at r.t

2- Heat to $100^{\circ} \mathrm{C} / 1 \mathrm{~h}$

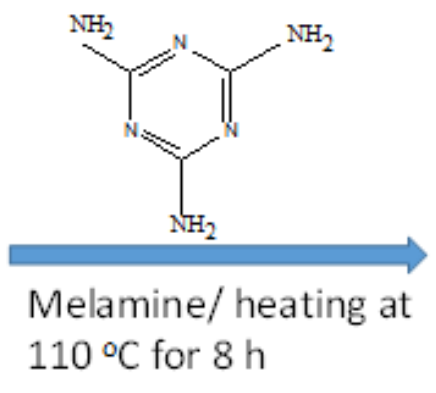
(II)<smiles></smiles><smiles>CC(O)(O)C(C)(O)OP(=O)(C(C)(C)O)C(C)(O)O</smiles>

(III)

\section{Figure 1}

\section{A schematic representation for synthesis of MtAPPM}




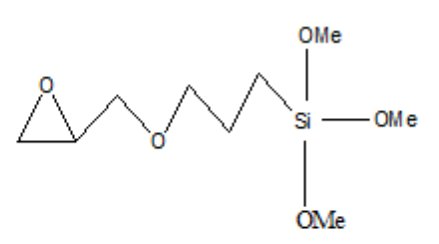

Hydrolysis of GPTMS

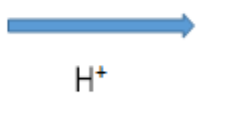

(III) (IV)

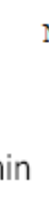

(III) (IV)

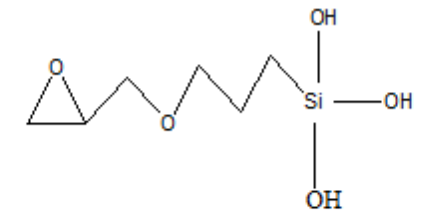

(IV)

Figure 2

Hydrolysis of 3-glycidyloxy propyltrimethoxy silane Mechanism of the coating process and formulation of crosslinking with cellulosic fabric. 


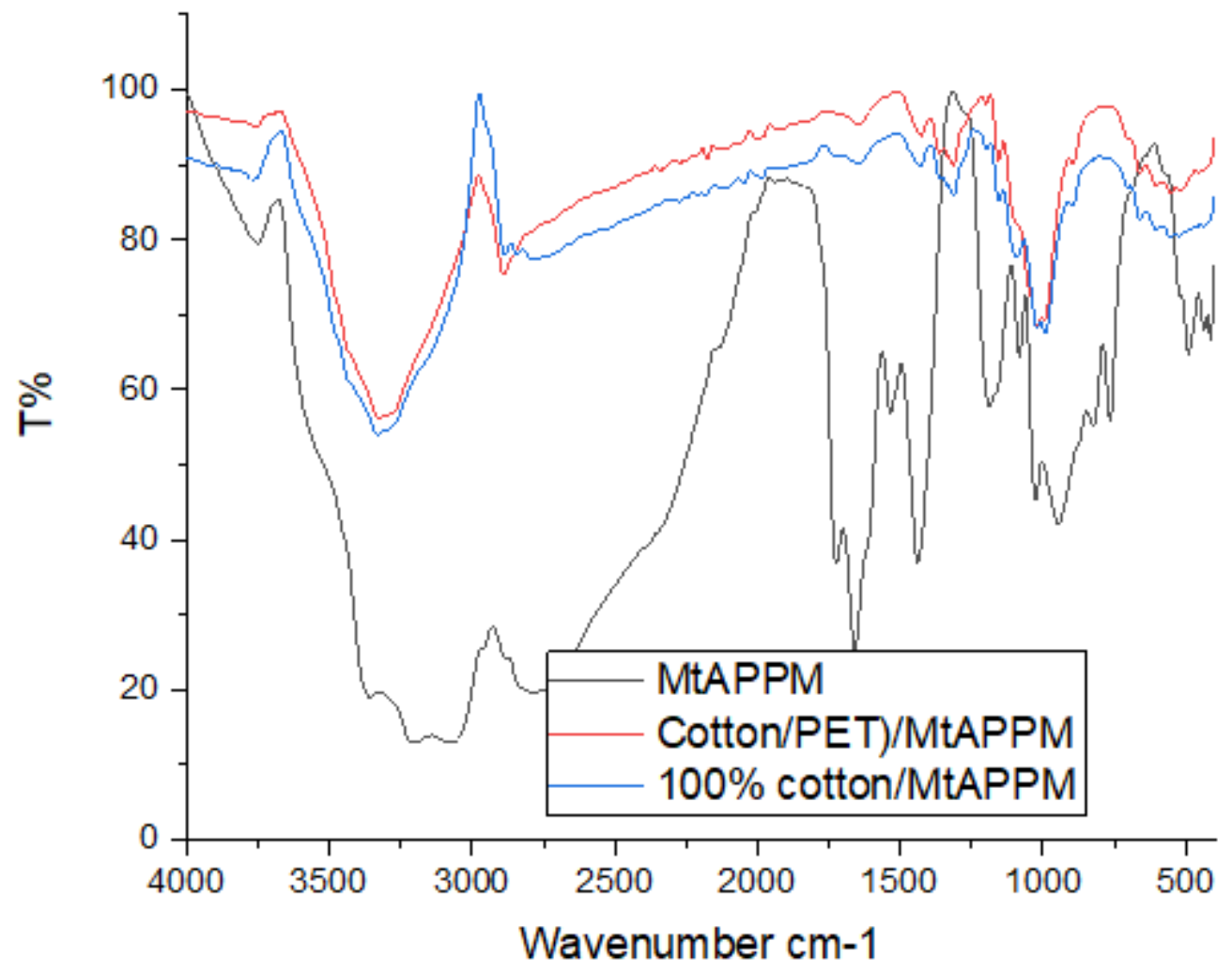

Figure 3

FTIR of MtAPPM, Cotton/MtAPPM and Cotton/PET(50/50\%)/MTAPPM. 


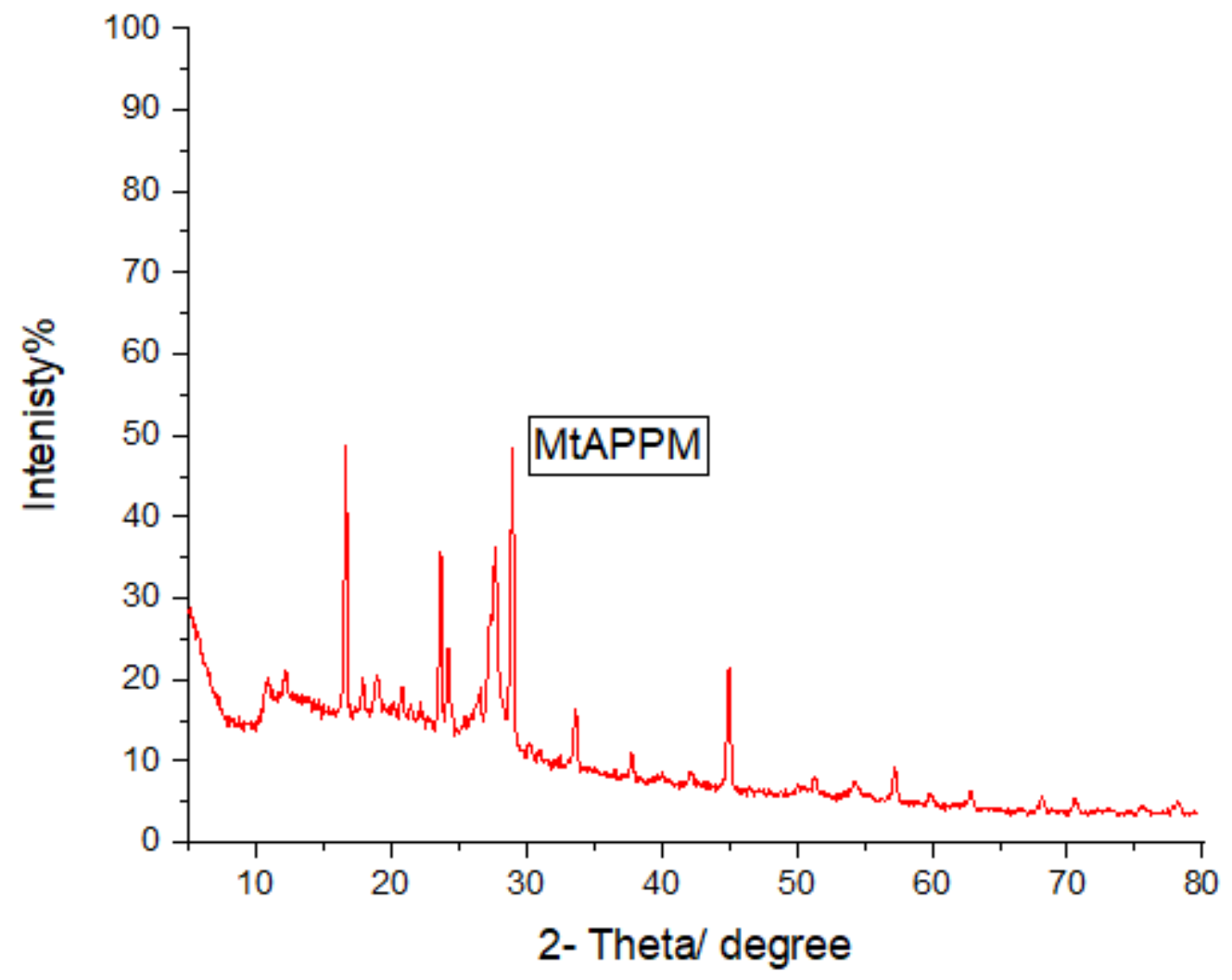

Figure 4

XRD of MtAPPM 


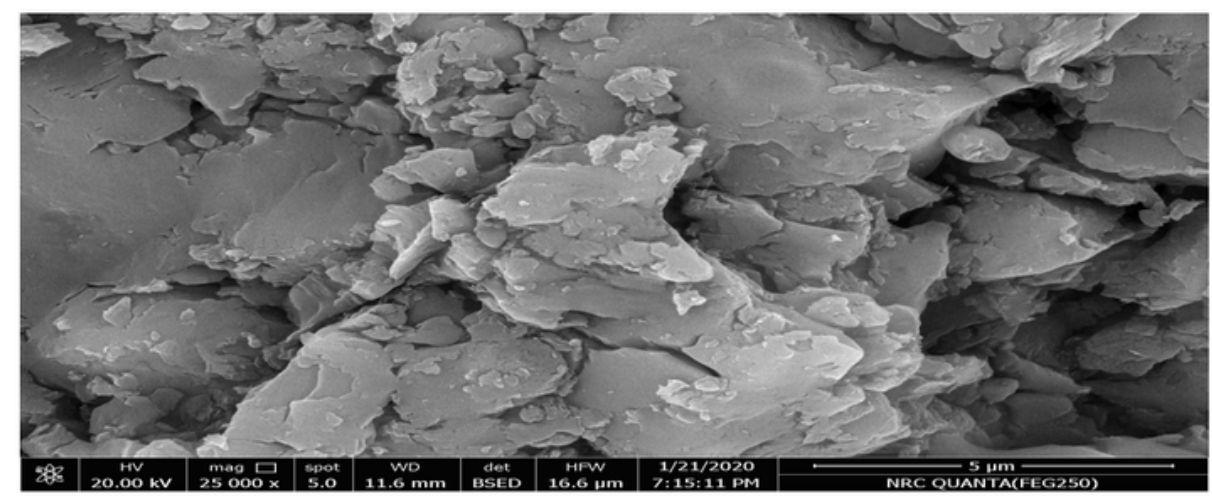

\section{a}
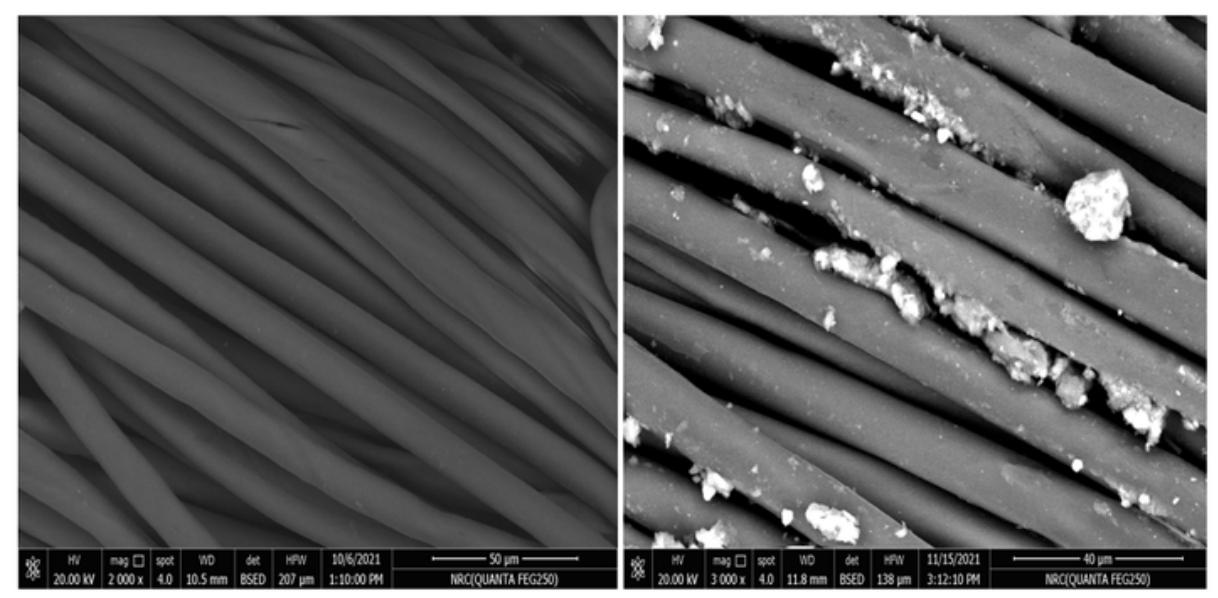

b

c
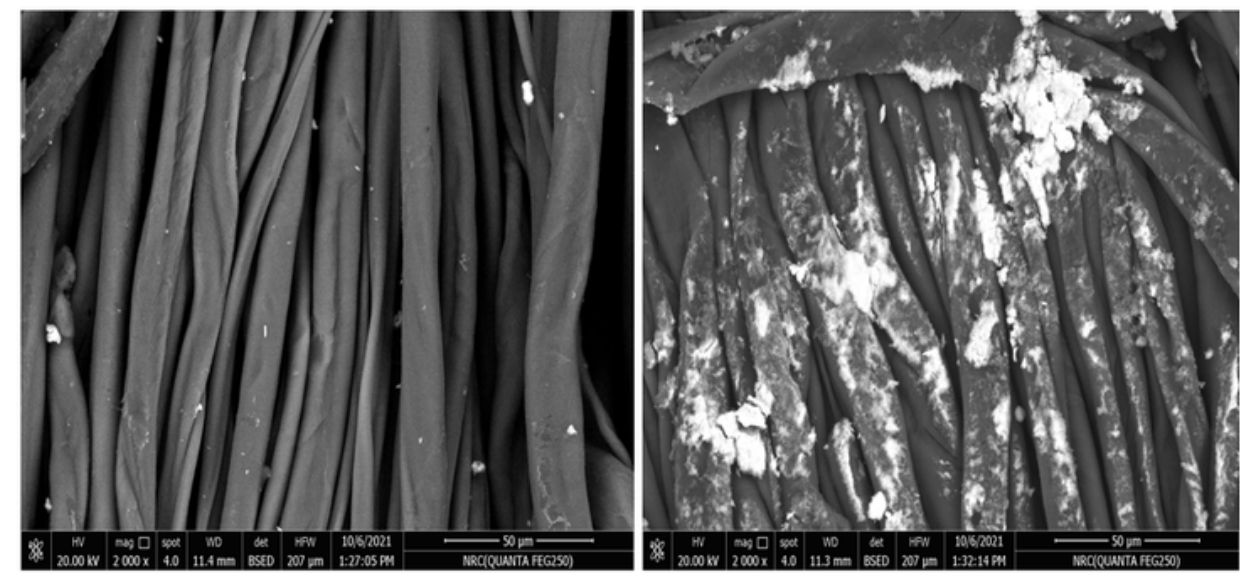

d

e

Figure 5

SEM of a)MtAPPM, b) $100 \%$ Cotton, c) $100 \%$ Cotton/MtAPPM, d) Cotton/PET (50/50) and e) Cotton/PET (50/50)/MtAPPM. 


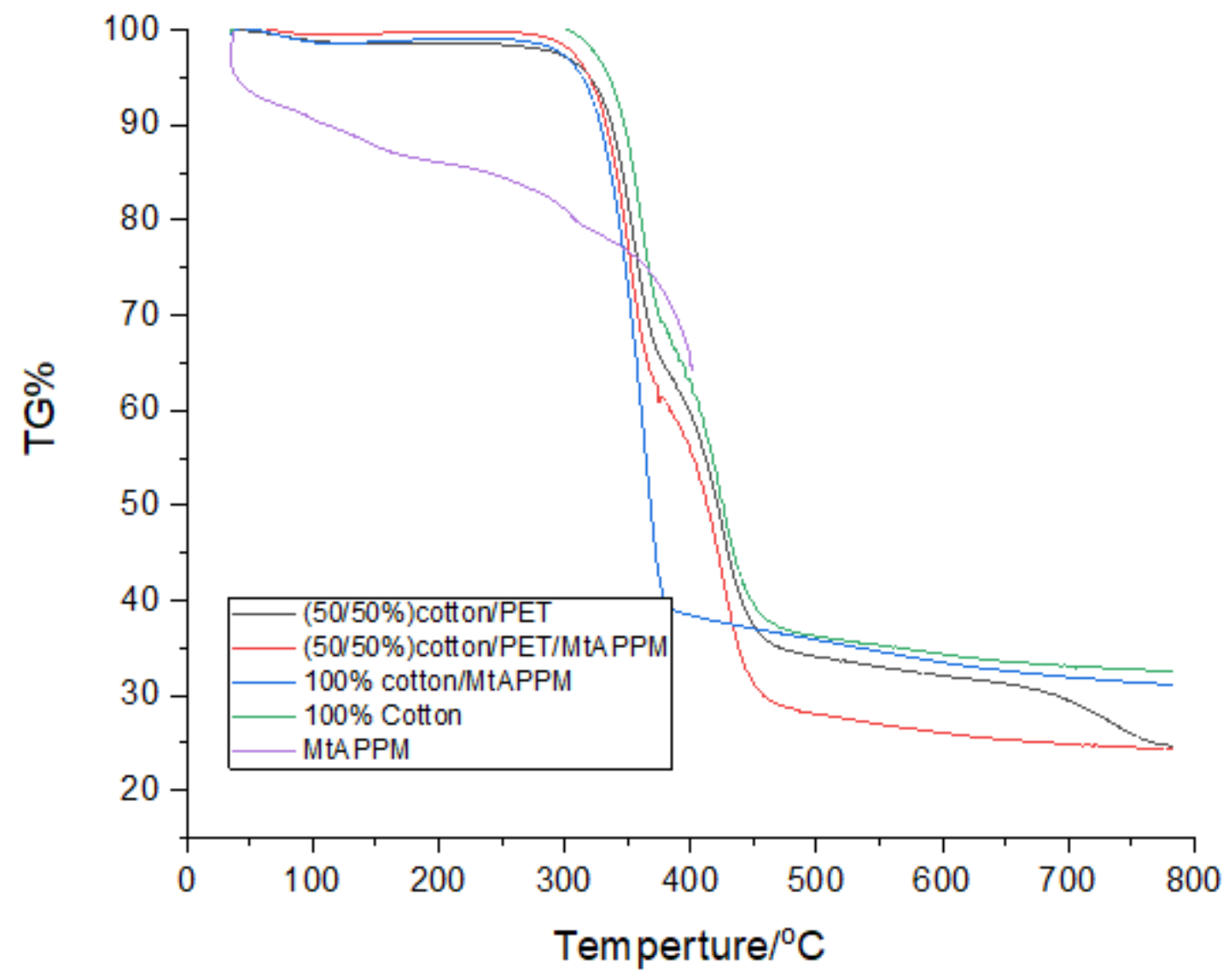

Figure 6

TGA of MtAPPM, $100 \%$ Cotton, $100 \%$ Cotton/MtAPPM, Cotton/PET (50/50) and) Cotton/PET (50/50)/MtAPPM. 


\section{Figure 7}

Photographs show ignition effect on the tested samples 1) $100 \%$ cotton-blank, 2) $(50 / 50)$ cotton/PET, 3) $100 \%$ cotton-blank /0.15MtAPPM and 4) cotton/PET /0.15MtAPPM. 